\title{
GIÁ TRİ CỦA CHỈ SỐ BÃO HÒA OXY TĨNH MACH TRUNG TÂM TRONG DỰ ĐOÁN KHẢ NĂNG THÔI THỞ MÁY Ở BẾNH NHÂN NHỒI MÁU CƠ TIM CẤP PHẢI THÔNG KHÍ NHÂN TẠO XÂM NHẬP
}

\section{TÓM TẮT}

Mục tiêu: Đánh giá khả năngdự đoán thất bại thôi thở máy (TTM) của chỉ số bão hòa oxy tĩnh mạch trung tâm (ScvO2) ở bệnh nhân nhồi máu cơ tim cấp (NMCT) nặng phải thổng khí nhân tạo xâm nhập (TKNTXN) >72 giờ. Phương pháp nghiên cứu: Nghiên cứu mô tá tiến cứu tiển hành tại khoa hồi sức tim mạch $\mathrm{C} 1$ bệnh viện Bach Mai trển nhóm bệnh nhân NMCT phải thiết lập TKNTXN có thời gian thở máy $>72$ giờ, đã đủ tiêu chuẩn TTM và được bác sĩ điều trị quyết định thực hiện thử nghiệm thở tự nhiên (TNTTN). Bệnh nhân sẽ được thu thập các thông tin về lâm sàng, cận lâm sàng đồng thời thực hiện lấy 2 mẫu khí máu tînh mach trung tâm vào 2 thời điểm ngay trước (T1) và phút thứ 30 (T2) của TNTTN. Kết quả: Có 25 bệnh nhân được đưa vào nghiên cứu, trong đó có 14 bệnh nhân TTM thành công và 11 bệnh nhân TTM thất bai. ScvO2 và tần số tim ở thời điểm T2 khác biệt có ý nghĩa thống kê giữa 2 nhóm $(69.87 \pm 3.9 \%$ và $63.84 \pm 6.54 \% ; \quad p=0.009 ; 103.5$ (99.5-107) và $111.0(106-113) ; p=0.008)$. Nghiên cứu của chúng tôi cho thây mức giảm ScvO2 lớn hơn $4.5 \%$ có khả năng dự đoánthất bai của quá trình TTM với độ nhạy là $72.7 \%$, độ đặc hiệu là $85.7 \%$. Kết luận: Sự sut giảm của chỉ số ScvO2(\%) giữa 2 thời điểm ngay trước và phút thứ 30 trong quá trình thực hiện TNTTN có thể dư đoán khả năng thất bại TTM ở bệnh nhân NMCT năng phải thở máy.

Tư khóa: ScvO2; Nhồi máu cơ tim cấp; Thông khí nhân tạo xâm nhập

\section{SUMMARY}

\section{VALUE OF CENTRAL VENOUS OXYGEN SATURATION TO DETECT WEANING FAILUREIN SEVERE ACUTE MYOCARDIAL INFRACTIONWHO MUST INVASIVE MECHANICAL VENTILATION}

Objectives: To evaluate the ability of central venous oxygen saturation (ScvO2) to detect weaningfailure(WF) in severe acute myocardial infraction(MI) who must invasive mechanical ventilation (MV) $>72$ hours. Methods: prospective observational study was conducted at cardiac intensive care unit C1 Bach Mai Hospital in severe MI needed mechanical ventilation $>72$ hours, fulfilling of the

\footnotetext{
${ }^{1}$ Bệnh viện Đa khoa 115 Nghệ An

${ }^{2}$ Trường Đại học Y Hà Nội

Chịu trách nhiệm chính: Hồ Đức Manh

Email: xpart201vn@gmail.com

Ngày nhận bài: 25.6.2021

Ngày phản biện khoa học: 19.8.2021

Ngày duyệt bài: 15.8.2021
}

\author{
Hồ Đức Mạnh', Phạm Minh Tuấn ${ }^{2}$
}

weaning criteria and have the clinical decision for spontaneous breathing trial (SBT). We collected the clinical, subclinical information and 2 samples of central venous blood gas before the SBT (T1) and $30^{\text {th }}$ min of SBT(T2). Result: Twenty five patients were enrolled in the study, there were fourteensuccessful weaning patients and eleven failed weaning patients. At the T2, ScvO2 decreased significantly while the heart increased significantly between two group $(69.87 \pm 3.9 \%$ vs $63.84 \pm 6.54 \% ; p=0.009 ; 103.5(99.5-$ 107) vs $111.0(106-113) ; p=0.008)$. In our study, a reduction of ScvO2 by $>4.5 \%$ between before and the $30^{\text {th }}$ min of SBT can predict weaning failure with sensivity $72.7 \%$, Specificity $85.7 \%$ and odds ratio 16 (confidence interval $=2.165-118.27, \mathrm{p}=0.005$ ). Conclusion: reduction of $\mathrm{ScvO} 2$ between before and the $30^{\text {th }} \mathrm{min}$ of SBT can predictability in weaning failure detection in severe myocardial infraction who needs invasive mechanical ventilation.

Keywwords: ScvO2; Myocardial infraction; Mechanical ventilation

\section{I. ĐẶT VẤN ĐỀ}

Thôi thở máy (TTM) là một khâu quan trọng trong chăm sóc bệnh nhân nặng, thành công của TTM là yếu tố quyết định thành công của thông khí nhân tạo xâm nhập. Do thở máy kéo dài gây nên nhiều nguy về viêm phổi, chấn thương phổi... nênvấn đề cố gắng ngừng thông khí nhân tạo xâm nhập sớm nhất khi tình trạng bệnh nhân cho phép luôn được các nhà lầm sàng đồng thuận từ lâu. Mặc dù vậy, một quyết định quá sớm hay cố gắng TTM kéo dài không hiệu quả dẫn đến thất bại của quá trình này kéo theo việc đặt lại nội khí quản, thiết lập lại thông khí nhẩn tạo cũng làm tăng thời gian thở máy, tăng thời gian nằm viện và tỉ lệ tử vong ${ }^{1}$.

TTM là một quá trình thay đổi về huyết động và thông khí, gây nên sự ảnh hưởng không nhỏ lên bệnh nhân và tác dụng này được khuyếch đại trên nhóm bệnh nhân nặng với chức năng tim - phổi không ổn định. Tác động về mặt huyết động của TTM bao gồm 3 xu hướng chính²: (1)Giảm áp suất lồng ngực gây tăng hồi lưu tĩnh mạch làm tăng tiên gánh thất trái. (2)Giảm áp lực mạch máu phổi, gây giảm hậu gánh thất phải và tăng đổ đầy thất trái.(3)Tăng áp lực xuyên thành gây tăng hậu gánh thất trái. Tác động về mặt hô hấp của TTMM lên bênh nhân bao gồm²: (1)Tăng công hô hấp. (2)Giảmthông khí, giảm oxy hóa máu, xẹp phế nanggóp phần 
gây tăng kháng trở mạch máu phổi.(3)Mất đi tác động của PEEP lên phế nang, có thể làm mất cân bằng thủy tĩnh trong phế nang, ứ dịch khoảng kẽ, gây giảm compliance phổi và tăng resistance phổi. Ngoài những yếu tố trên, hoạt hóa hệ giao cảm trong quá trình TTM cũng gây nên ảnh hưởng không nhỏ trên quá trình cung - cầu oxy của bệnh nhân.Việc gia tăng hoạt động của các cơ hô hấp nhằm bù trừ cho các biển đổi trong quá trình TTM kéo theo sự tăng mạnh nhu cầu oxy, qua đó đòi hỏi cung lượng tim tăng tương ứng, song song với đó là việc tăng lên của tiền gánh và hậu gánh dẫn đến gánh nặng phải nhận của tim là rất lớn.

Nhồi máu cơ tim cấp (NMCT) là bệnh lý thường gặp tại các khoa hồi sức tim mạch và là nguyên nhân hàng đầu của bệnh nhân suy tim cấp, thông khí nhân tạo xâm nhập hay thở máy là một biện pháp cứu cánh cho tình trạng suy hô hấp của NMCT cấp nặng. Rõ ràng trền một trái tim với một hệ mạch vành đã tổn thương, một chức năng tim đã suy giảm nặng thì mối cần bằng cung - cầu oxy của cơ thể đó là vô cùng mong manh. Chính vì lẽ đó, khi các yếu tố cơ bản của cơ thể như khả năng oxy hóa máu của phổi, thăng bằng nội môi, ý thức, tình trạng nhiếm trùng, ... của cơ thể đã tương đối ổn định thì khả năng đảm bảo được cân bằng cung - cầu oxy khi TTM của tim quyết định rất lớn vào việc thành công hay thất bại của quá trình TTM ở bệnh nhân NMCT ${ }^{3}$.

Chưa có một thang điểm hay biện pháp nào có thể tiên đoán hoàn toàn kết cục quá trình TTM bởi có rất nhiều yếu tỗ ảnh hưởng tới kết quả này. Xét riêng trên phương diện thất bại TTM do nguyên nhân tim mạch, hiện nay, đang được các tác giả đang tập trung nghiên cứu. Các phương pháp này đều có nguyên lý chung là khảo sát sự thay đổi của cơ thể trong thời gian thực hiện TNTTN bằng thăm dò huyết động (Picco, siêu âm tim qua thành ngực...), xét nghiệm máu (pro BNP, ScvO2) hay siêu âm phổi ${ }^{4}, 5$. Mặc dù vậy, trong điều kiện nước ta hiện nay, các kĩ thuật thăm dò huyết động hay siểu âm vẫn chưa trở thành một thăm dò̀ thường quy vì đòi hỏi nhiêu về con người và máy móc.

ScvO2 với mối tương quan chặt chẽ với SvO2, được coi là một sự thay thế cho SvO2 trong lâm sàng, có khả năng đánh giá cân bằng cung - cầu oxy trong cơ thể ${ }^{6}$. Nghiên cứu của Jubrand và Tobin cho thây ở các bệnh nhân thành công TTM, nhu cầu oxy tăng lên không quá nhiêu, trong khi đó quá trình vận chuyển cung cấp oxy tăng lên rất nhiều qua đó kéo theo mức chiết oxy cần thiết không tăng, vì vậy $\mathrm{SvO2} \mathrm{ở} \mathrm{nhóm}$ bệnh nhân này là không đổi. Ngược lại, trong nhóm TTM thất bại, mặc dù tiêu thụ oxy tăng vọt nhưng cung cấp oxy không tăng mà ngược lại có xu hướng giảm đi và kéo theo mức chiết oxy tăng lên, qua đó kéo theo sự giảm xuống của chỉ số SvO2 (61.3 $55.8 \%$ xuống $51.5 \pm 7.9 \%)^{7}$. Tương tự,nghiên cứu của Teixeira, nhận thấy mức giảm của ScvO2 lần lượt là $4.5 \%$ có khả năng dự đoán thất bại TTM với độ nhạy và độ đặc hiệu $\mathrm{caO}^{5}$.

Chính vì vậy chúng tôi tiến hành nghiên cứu này nhằm đánh giá giá trị của $\mathrm{ScvO2}$ trong dự đoán khả năng TTM ở nhóm bệnh nhân NMCT nặng (thở máy > 72giờ).

\section{II. ĐỐI TƯỢNG VÀ PHƯƠNG PHÁP NGHIÊN CỨU}

Đối tượng nghiên cứu: Thời gian từ tháng 6/2020 tới tháng 8/2021 tại khoa C1 tim mạch bệnh viện Bạch Mai. Chúng tôi tiến hành thu thập thổng tin lâm sàng, cận lâm sàng, xét nghiệm khí máu tĩnh mach trung tâm trên nhóm bệnh nhân đã được chẩn đoán nhồi máu cơ tim cấp, thở máy $>72$ giờ vì suy hô hấp, sau khi tình trạng đã ổn định, được xét tiến hành thôi thở máy khi đủ các tiêu chuẩn thực hiện thử nghiệm thở tự nhiên ${ }^{8}$. Bao gồm: a, Không rối loạn tri giác, không còn tác dụng của an thần giãn cơ; $b$, Nhiểm trùng hô hấp được bác sĩ lâm sàngđánh giá ổn định (lượng đàm giảm, không sốt, các chỉ số viêm giảm, oxy hóa máu cải thiện...); c,Khả năng oxy hóa máu phù hợp ( $\mathrm{PaO} 2 / \mathrm{FiO}^{2}$ $>150 \mathrm{mmHg}$ ); d, Huyết động ổn định (nhịp tim $<140 \mathrm{l} / \mathrm{p}$, không dùng vận mạch hoặc dùng ở mức rất thấp); e,Hemoglobin $>7 \mathrm{~g} / \mathrm{dL}$; $\mathrm{f}$, Không rối loạn thân nhiệt; $g$, Ho khạc tốt; $h$, Cân bằng điện giải. Tiêu chuẩn loại trừ: loạn nhịp hoặc tử vong trong quá trình TTM, dị dạng lî̀ng ngực hoặc bất thường đường thở, bệnh nhân mở khí quản, rối loạn ý thức, có bệnh lý thần kinh - cơ, mất máu cấp tính, tiền sử COPD, bất thường hồi lưu tĩnh mạch hay shunt tuần hoàn, bệnh nhân hoặc người nhà không đồng ý tham gia nghiên cứu.

Quy trình thôi thở máy: Sau khi được bác sĩ lâm sàng xác định đủ điều kiện tiến hành thử nghiệm thở tự nhiên (TNTTN) đã nói ở trên, tiến hành TTM bằng phương pháp hỗ trợ áp lực tối thiểu $(\leq 7 \mathrm{cmH} 2 \mathrm{O}, \leq$ PEEP $5 \mathrm{cmH} 2 \mathrm{O})$.

Tiến hành TNTTN trong vòng 2 tiếng, đánh giá thành công TNTTN và ra quyết định rút NKQ.Thất bại TTN được định nghĩa là thất bại TNTTN hoặc phải đặt lại NKQ trong vòng 48giờ sau rút nội khí quản 3,5 .

Phương pháp thống kê: Thống kê mô tả 
bằng trung bình và độ lệch chuẩn với số liệu phân bố chuẩn, trung vị và khoảng tứ phân vị với phân bố không chuẩn. Kiểm định sự khác biêt bằng $\mathrm{t}$ test độc lập và mann whitney $\mathrm{u}$ test. Kiểm đinh mối liên quan giữa các biến đinh tính bằng test $\chi 2$ hoặc Fisher với $\mathrm{p}<0.05$. Sử dụng đường cong ROC để tìm điểm cut - off tối ưu với test dự đoán. Sử dụng hồi quy logistic đa biến tìm ra yếu tố dự đoán kết quả độc lập.

\section{KẾT QUẢ NGHIÊN CỨU}

Từ tháng 6/2020 tới tháng 8/2021 tại khoa C1 tim mạch bệnh viện Bạch Mai, chúng tôi ghi nhận 25 bệnh nhân đã được chẩn đoán nhồi máu cơ tim cấp, suy hô hấp, thở máy>72 giờ,đủ các tiêu chuẩn thực hiên TNTTN.Trong số các bênh nhân này, thất bại thôi thở máy có $11 / 25$ bệnh nhân chiếm 44\%.

Bảng 1: Đăc điểm bênh nhân nghiên cứu:

\begin{tabular}{|c|c|c|c|}
\hline Đă̆c điếm & TTM thành công (n=14) & TTM thất bại (n=11) & P value \\
\hline Giới nam/nữ & $11 / 3(78.6 \% / 21.4 \%)$ & $3 / 1(75 \% / 25 \%)$ & 0.604 \\
\hline Tuối & $72.29 \pm 9.343$ & $72.91 \pm 10.144$ & 0.875 \\
\hline BMI & $20.8 \pm 2.5$ & $21.7 \pm 1.9$ & 0.326 \\
\hline Sốc tim* & $2 / 12(14.3 \% / 85.7 \%)$ & $7 / 4(63.6 \% / 36.4)$ & $\mathbf{0 . 0 1 7}$ \\
\hline Stemi/Nstemi & $7 / 7(50 \% / 50 \%)$ & $7 / 4(63.6 \% / 36.4)$ & 0.689 \\
\hline Tái tưới máu (có/không) & $9 / 5(64.3 \% / 35.7 \%)$ & $5 / 6(45.5 \% / 54.5 \%)$ & 0.346 \\
\hline Viêm phốí (có/không) & $7 / 7(50 \% / 50 \%)$ & $9 / 2(81.8 \% / 18.2 \%)$ & 0.208 \\
\hline Suy thận cấp (có/không) & $3 / 11(21.4 \% / 78.6 \%)$ & $5 / 6(45.5 \% / 54.5 \%)$ & 0.187 \\
\hline Thời gian thơ máy & $5.0(4.0-6.0)$ & $7.0(5.0-7.0)$ & 0.082 \\
\hline
\end{tabular}

*Lúc nhâp khoa C1.

Tình trạng sốc tim ở bệnh nhân thời điểm nhập khoa C1 có liên quan tới kết cục của quá trình TTM với $\mathrm{p}<0.05$

Bảng 2: Cận lâm sàng trước thử nghiệm thở tự nhiên:

\begin{tabular}{|c|c|c|c|}
\hline Thông số & TTMthành công & TTMthất bại & P value \\
\hline CRPhs(mg/dL) & $4.5(3-10.75)$ & $9.0(7-17)$ & $\mathbf{0 . 0 1 1}$ \\
\hline Creatinin(mmol//L) & $113(88.75-147.5)$ & $143(123-223)$ & 0.071 \\
\hline GFR(ml/p/1.73 & $50(34-68.75)$ & $45(24-50)$ & 0.162 \\
\hline ProBNP(pg/mL) & $1573.5(776.53-2830.25)$ & $2977(1186-4139)$ & 0.198 \\
\hline TroponinT(ng/L)* & $822(382.4-1276.5)$ & $2558(527-5047)$ & 0.071 \\
\hline Lactate $(\mathrm{mmol} / \mathrm{L})$ & $2.53 \pm 1.09$ & $2.57 \pm 0.97$ & 0.923 \\
\hline
\end{tabular}

*Lấy giá trị lúc nhập C1 trong vòng 48h (lấy giá trị cao nhất)

Có sự khác biệt giữa chỉ số CRPhs ở nhóm TTM thất bại với nhóm TTM thành công với $p=0.011$.

Bảng 3: Khí máu động mach, huyết hoc và thông số cơ học phổi:

\begin{tabular}{|c|c|c|c|}
\hline Thông số & TTM thành công & TTM thất bại & P value \\
\hline $\mathrm{pH}(\mathrm{a})$ & $7.429 \pm 0.042$ & $7.436 \pm 0.046$ & 0.747 \\
\hline $\mathrm{PaO2}$ & $121.543 \pm 28.00$ & $123.455 \pm 34.869$ & 0.884 \\
\hline $\mathrm{PaO} 2 / \mathrm{fiO} 2$ & $283.375 \pm 51.319$ & $256.136 \pm 44.725$ & 0.177 \\
\hline $\mathrm{SaO} 2$ & $98.571 \pm 0.9442$ & $98.564 \pm 1.0893$ & 0.985 \\
\hline HCO3-(a) & $24.25(23.58-25.95)$ & $24.2(22.4-31.2)$ & 1.00 \\
\hline $\mathrm{PaCO} 2$ & $38.079 \pm 3.751$ & $39.3 \pm 4.669$ & 0.475 \\
\hline Hemoglobin $(\mathrm{g} / \mathrm{l})$ & $108.14 \pm 17.514$ & $99.45 \pm 20.878$ & 0.269 \\
\hline Hemantocit (\%) & $32.81 \pm 4.66$ & $31.46 \pm 5.81$ & 0.525 \\
\hline WBC (G/L) & $13.08 \pm 3.15$ & $14.11 \pm 3.6$ & 0.459 \\
\hline Cstat*(ml/cmH2O) & $55.3(47.9-57.7)$ & $48.2(47.3-54.7)$ & 0.118 \\
\hline Resistance*(cmH2O/L.s) & $6.4 \pm 1.66$ & $7.64 \pm 2.63$ & 0.165 \\
\hline $\mathrm{MIP}(\mathrm{cmH} 2 \mathrm{O})^{* *}$ & $36.5(35.75-38)$ & $34(32-38)$ & 0.104 \\
\hline Tidal volume $(\mathrm{ml})^{* *}$ & $439(385.75-472.5)$ & $410(342-454)$ & 0.381 \\
\hline $\mathrm{TV} / \mathrm{kg}(\mathrm{ml} / \mathrm{kg})^{* *}$ & $7.35(6.975-7.65)$ & $6.5(6.3-7.5)$ & 0.075 \\
\hline Srbi** & $53.5(47.425-67.85)$ & $58.8(44-74.1)$ & 0.477 \\
\hline
\end{tabular}

*Thực hiện trước khi dừng an thần, trước TNTTN trong vòng 24h.

**Phút thứ 5 TNTTN.

Bảng 4: Thông số lâm sàng và khí máu tĩnh mạch trung tâm ngay trước khi tiến hành TNTTN và thời điểm 30 phút của TNTTN: 


\begin{tabular}{|c|c|c|c|c|c|c|}
\hline \multirow{2}{*}{ Thông số } & \multicolumn{3}{|c|}{ Ngay trước TNTTN } & \multicolumn{3}{c|}{ Phút thứ 30 TNTTN } \\
\cline { 2 - 7 } & $\begin{array}{c}\text { TTM } \\
\text { thành công }\end{array}$ & $\begin{array}{c}\text { TTM } \\
\text { thất bại }\end{array}$ & $\mathbf{P}$ & $\begin{array}{c}\text { TTM } \\
\text { thành công }\end{array}$ & $\begin{array}{c}\text { TTM } \\
\text { thất bại }\end{array}$ & $\mathbf{p}$ \\
\hline $\mathrm{pH}(\mathrm{v})$ & $7.39 \pm 0.028$ & $7.39 \pm 0.065$ & 0.623 & $7.39 \pm 0.035$ & $7.38 \pm 0.048$ & 0.721 \\
\hline $\mathrm{PcVO} 2$ & $44.12 \pm 4.14$ & $42.55 \pm 5.34$ & 0.414 & $43.33 \pm 5.67$ & $40.04 \pm 5.32$ & 0.152 \\
\hline ScvO2 & $69.79 \pm 2.56$ & $70.6 \pm 4.6$ & 0.606 & $69.87 \pm 3.9$ & $63.84 \pm 6.54$ & $\mathbf{0 . 0 0 9}$ \\
\hline HCO3- & 25.2 & 25.5 & 0.848 & 25.5 & 24.6 & 1.00 \\
\hline PcvCO2 & $(24.33-25.8)$ & $(23.1-31.5)$ & & $(24.2-26.13)$ & $(23.2-32.8)$ & \\
\hline MAP & $83.11 \pm 2.139$ & $43.84 \pm 4.57$ & 0.604 & $43.51 \pm 3.199$ & $46.32 \pm 4.20$ & 0.071 \\
\hline Nhịp thở & $20.54 \pm 10.97$ & $77.73 \pm 6.82$ & 0.067 & $85.07 \pm 10.98$ & $79 \pm 7.7$ & 0.134 \\
\hline Tần số tim & $97.36 \pm 8.68$ & $21(18-27)$ & 0.44 & $25.43 \pm 2.85$ & $27.45 \pm 3.27$ & 0.111 \\
\hline CVP & $11.36 \pm 3.46$ & $97.45 \pm 9.97$ & 0.979 & $103.5(99.5-107)$ & $111.0(106-113)$ & $\mathbf{0 . 0 0 8}$ \\
\hline SpO2 & $96.57 \pm 1.65$ & $95.27 \pm 4.31$ & 0.082 & $13.5 \pm 3.23$ & $16.64 \pm 4.48$ & 0.053 \\
\hline Bang & & 0.069 & $93(92-93.25)$ & $92(91-93)$ & 0.09 \\
\hline
\end{tabular}

Bảng 5: Hồi quy logistic đa biến các yêu tố liên quan tới thất bại TTM:

\begin{tabular}{|c|c|c|}
\hline Thông số & $\begin{array}{c}\text { Hồi quy đơn } \\
\text { biên }(\mathrm{p})\end{array}$ & $\begin{array}{c}\text { Hồi quy đa } \\
\text { biến }(\mathrm{p})\end{array}$ \\
\hline$\Delta \mathrm{ScvO2}(\%)^{*}$ & 0.015 & $\mathbf{0 . 0 4 6}$ \\
\hline$\Delta \mathrm{HR}(\%)^{* *}$ & 0.035 & 0.117 \\
\hline $\mathrm{CRP}$ & 0.129 & 0.153 \\
\hline
\end{tabular}

${ }^{*} \Delta \mathrm{ScvO} 2(\%)=\mathrm{ScvO2}(\mathrm{T} 1)-\mathrm{ScvO} 2(\mathrm{~T} 2)$

$* * \Delta \mathrm{HR}(\%)=(\mathrm{HR} 1-\mathrm{HR} 2) / \mathrm{HR} 1.100(\%)$

Hồi quy logistic cho thây chỉ có $\Delta \mathrm{ScvO2}(\%)$ là biến độc lập duy nhất có khả năng dự đoán thất bại TTM.

Điểm cắt mức độ giảm ScvO2 4.5\% giữa thời điểm ngay trước TNTTN và phút thứ 30 của TNTTN có giá trị tiên lượng tốt, với độ nhạy là $72.7 \%$, độ đặc hiệu là $85.7 \%$, PPV $80 \%$, NPV $80 \%$ và diện tích dưới đường cong ROC: $A U C=$ $0.854(p=0.007)$

Đồ thị 1: Đường cong ROC cho khả năng dự đoán thất bại TTM:

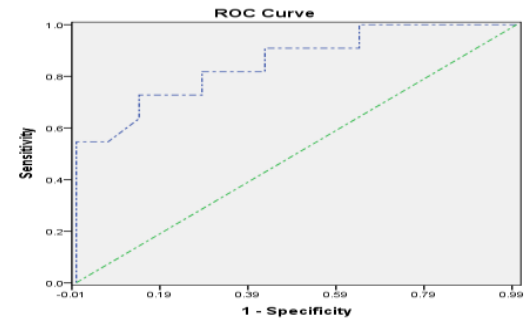

\section{BÀN LUẬN}

Kết quả nghiên cứu của chúng tôi cho thấy mức giảm của ScvO2(\%) 4.5\% giữa thời điểm ngay trước TNTTN và phút thứ 30 của TNTTN có thể dự đoán thất bại của quá trình TTM.

Lý giải cho kết quả nghiên cứu này, theo Boles, trên nhóm bệnh nhân NMCT nặng đã đủ điều kiện xét thôi thở máy, với tình trạng viêm phổi điều trị tương đối ổn định (không sốt, chỉ số bạch cầu giảm, oxy hóa máu tốt, lượng đàm và màu sắc đàm cải thiện), điện giải và toan kiềm không rối loạn, bệnh nhân ý thức tốt và không có bênh lý thần kinh - cơ, không có mất máu cấp tính, nguyên nhân gây nên khó TTM ở nhóm bệnh nhân này đó chính là do tăng tải của tuần hoàn và hô hấp ${ }^{3}$. Chúng tôi cho rằng việc mất cân bằng cung - cầu oxy trong quá trình cai thở máy do tăng nhu cầu oxy để thực hiện công hô hấp, đòi hỏi việc tăng hoạt động của tim nhằm cung cấp đủ oxy, trong khi đó chức năng của tim ở nhóm TTM thất bại có lẽ không còn "dự trữ" đủ để đáp ứng sự thay đổi này. Trong một nghiên cứu của Teboul và Liu, các tác giả này nhânn thây rằngmột trạng thái preload independence (độc lập tiền gánh) được đánh giá bằng test nâng chân thụ động có kết quả âm tính (CO tăng bé hơn $10 \%$ ) có khả năng dự báo một thất bại TTM do tim $\mathrm{cao}^{9}$. Điều đó gợi ý một điểu rằng thất bai TTM do tim sẽ tránh được khi mà bệnh nhân đạt được một trạng thái mà khi đó tim vẫn còn dự trữ khi tiền gánh đột ngột tăng lên, điều đó đặt ra việc quản lý tốt hợn cân bằng dịch trong cơ thể cũng như đánh giá khả năng làm việc của tim trong việc sẵn sàng TTM. Song song với đó nên là quá trình tối ưu hóa các tải của hồ hấp như: Điều trị viêm phổi tích cực; Bổ sung oxy đầy đủ hoặc thở máy không xẩm lấn sau rút nội khí quản; Giảm khoảng chết hô hấp(mơ khí quản); Điều trị phù nề thanh quản; Giảm tối đa các tác động áp lực lên hô hấp như chọc hút dịch màng phổi, đặt lại tư thế bệnh nhân, điều trị tăng áp lực ổ bụng; Giảm tiêu thụ oxy và kích thích giao cảm (giảm đau, dùng thuốc chống lo âu hợp lý).

\section{KẾT LUÂ̂N}

Sự sụt giảm của chỉ số ScvO2(\%) giữa 2 thời điểm ngay trước và phút thứ 30 trong quá trình thực hiện TNTTN có thể dự đoán khả năng thất bại TTM ở bệnh nhân NMCT nặng phải thở máy. 
TÀI LIÊU THAM KHẢO

1. Epstein, S. K.; Ciubotaru, R. L. Independent Effects of Etiology of Failure and Time to Reintubation on Outcome for Patients Failing Extubation. Am. J. Respir. Crit. Care Med.1998, 158 (2), 489-493.

2. Alviar, C. L.; Miller, P. E.; McAreavey, D.; Katz, J. N.; Lee, B.; Moriyama, B.; Soble, J.; van Diepen, S.; Solomon, M. A.; Morrow, D. A. Positive Pressure Ventilation in the Cardiac Intensive Care Unit. J. Am. Coll. Cardiol.2018, 72 (13), 1532-1553.

3. Boles, J.-M.; Bion, J.; Connors, A.; Herridge, M.; Marsh, B.; Melot, C.; Pearl, R.; Silverman, H.; Stanchina, M.; Vieillard-Baron, A.; Welte, $\mathrm{T}$. Weaning from Mechanical Ventilation. Eur. Respir. J.2007, 29 (5), 1033-1056.

4. Vignon, P. Cardiovascular Failure and Weaning. Ann. Transl. Med.2018, 6 (18), 354-354.

5. Teixeira, C.; da Silva, N. B.; Savi, A.; Vieira, S. R. R.; Nasi, L. A.; Friedman, G.; Óliveira, R. P.; Cremonese, R. V.; Tonietto, T. F.; Bressel, M. A. B.; Maccari, J. G.; Wickert, R.; Borges, L. G. Central Venous Saturation Is a Predictor of Reintubation in Difficult-to-Wean Patients. Crit. Care Med.2010, 38 (2), 491-496.
6. Walley, K. R. Use of Central Venous Oxygen Saturation to Guide Therapy. Am. J. Respir. Crit. Care Med.2011, 184 (5), 514-520.

7. Jubran, A.; Mathru, M.; Dries, D.; Tobin, M. J. Continuous Recordings of Mixed Venous Oxygen Saturation during Weaning from Mechanical Ventilation and the Ramifications Thereof. Am. J. Respir. Crit. Care Med.1998, 158 (6), 1763-1769.

8. MacIntyre, N. R.; Cook, D. J.; Ely, E. W.; Epstein, S. K.; Fink, J. B.; Heffner, J. E.; Hess, D.; Hubmayer, R. D.; Scheinhorn, D. J.; American College of Chest Physicians; American Association for Respiratory Care; American College of Critical Care Medicine. Evidence-Based Guidelines for Weaning and Discontinuing Ventilatory Support: A Collective Task Force Facilitated by the American College of Chest Physicians; the American Association for Respiratory Care; and the American College of Critical Care Medicine. Chest2001, 120 (6 Suppl), 375S-95S.

9. Liu, J.; Shen, F.; Teboul, J.-L.; Anguel, N.; Beurton, A.; Bezaz, N.; Richard, C.; Monnet, X. Cardiac Dysfunction Induced by Weaning from Mechanical Ventilation: Incidence, Risk Factors, and Effects of Fluid Removal. Crit. Care2016, 20 (1)

\title{
ĐĂC ĐIỂM Nô̂I SOI ĐƯờ'NG HÔ HẤP TRÊN TRONG GIẤC NGỦ TAO RA BẰNG THUỐC TRONG HộI CHỨNG NGỪNG THỞ TẮC NGHẼN KHI NGỦ
}

\author{
Trần Thị Hoa' ${ }^{1}$ Pham Trần Anh ${ }^{1}$, \\ Nguyễn Trung Anh ${ }^{2}$, Đào Đình Thi ${ }^{3}$, Nguyễn Nhật Linh ${ }^{3}$
}

\section{TÓM TẮT}

Mục tiêu: Mô tả đặc điểm đường hô hấp trên trong hội chứng ngừng thở tắc nghẽn khi ngủ. Phương pháp: Nghiên cứu in vivo, người đánh giá độc lập, thực hiện trên 12 bệnh nhân có mắc hội chứng ngừng thở tắc nghẽn khi ngủ mức độ năng qua đo đa ký giấc ngủ. Tất cả mẫu nghiên cứu được nội soi đường hô hấp trên bằng ống nội soi mềm qua đường mũi trong giấc ngủ được tạo ra bằng thuốc gây mê. Đánh giá vị trí, cấu hình xẹp và mức độ xẹp theo phân loại VOTE của Kerizian và cộng sự năm 2011 [1]. Kết quả: Mô tả đặc điểm DIŚE ở 12 bênh nhân ngừng thở tắc nghẽn khi ngủ mức độ nặng (có chỉ số AHI 53.18 $\pm 15.75 /$ giờ, Chỉ số khối cở thể $25.33 \pm 1.95$ $\mathrm{kg} / \mathrm{m}(2)$, tuổi $45.75 \pm 13.53$ tuổi, tỷ lệ nữ:nam là 1:2) trước khi lựa chon kế hoach phẫu thuật. Qua phân tích có tới 7 bệnh nhân (58.3\%) có xẹp nhiêu hơn một tầng tại đường hô hấp trên và bệnh nhân xẹp đa tầng

\footnotetext{
1 Trường Đại hoc Y Hà Nôi

²Bênh viên Lão khoa Trung Uơng

${ }^{3}$ Bềnh viện Tai Mũi Họng Trung Ương

Chịu trách nhiệm chính: Trần Thị Hoa

Email: hoatran95.hmu@gmail.com

Ngày nhận bài: 21.6.2021

Ngày phản biên khoa hoc: 18.8.2021

Ngày duyệt bài: 26.8.2021
}

có chỉ số $A H I$ và BMI cao hơn bênh nhân xẹp đơn tânng có ý nghĩa thống kê với $\mathrm{p}<0.05$ (56.54 16.67 so với $51.64 \pm 16.39$ và $25.83 \pm 1.75$ so với $24.98 \pm 2.14$ ) và các vị trí xẹp nắp thanh thiệt hay xẹp họng miệng, màn hầu, đáy lưỡi có chỉ số ẢHI khác biệt và sự khác biệt về tuổi và chênh lệch giới giữa nhóm bệnh nhân xẹp đa tầng và đơn tầng không có ý nghĩa thống kê (p>0.05). Kết luận: Việc thực hiện DISE phát hiện tỷ lệ xẹp đa tầng tại đường hồ hấp trên ở bệnh nhân ngừng thở tắc nghẽn mức độ nặng là cao. Do vậy, chúng tôi đề xuất DISE là công cụ lựa chọn đánh giá đường hô hấp trên cho những bệnh nhân ngừng thở tắc nghẽn mức độ nặng có chỉ định phẫu thuật.

Tư khóa: Nôi soi đường thở khi ngủ, phẫu thuât hội chứng ngừng thở tắc nghẽn khi ngủ, đánh giá đường hô hâp trên khi ngủ, thuốc trong nội soi.

\section{SUMMARY}

\section{DRUG INDUCED SLEEP ENDOSCOPY IN} OBSTRUCTIVE SLEEP APNEA SYNDROME

Objectives: Upper airway characteristics in obstructive sleep apnea syndrome. Methods: In vivo study performed on 12 patients with severe OSA syndrome in PSG. All objects underwent upper airway endoscopy with a soft trans-nasal endoscope during sleep induced with the anesthetic. Evaluation of the location, profile and degree of collapse according to the VOTE classification of Kerizian et al 2011[1] 